\title{
Quantification of 4-Oxiranyl Methoxy-9h-Carbazole a Genotoxic Impurity in Carvedilol Drug Substances by Lc-Ms
}

\author{
M. Srinivasa Rao ${ }^{1 *}$, Sumathi V. Rao ${ }^{1}$, U.K.Ray ${ }^{1}$, G.Sri Siva Kumar ${ }^{1}$, Hemant Kumar Sharma ${ }^{1}$ and K.Mukkanti ${ }^{2}$
}

${ }^{1}$ Department of Analytical research, Aurobindo Pharma Research Centre, 313 Bachupally, Qutubullapur Mandal, Hyderabad - 500090, India ${ }^{2} \mathrm{Head}$ of Centre for Pharmaceutical sciences, JNTU Institute of sciences \& Technology, Kukatpally, Hyderabad - 500085, India

\begin{abstract}
LC-MS multiple reaction monitoring (MRM) method had been evaluated for the determination of the very low level of 4-Oxiranylmethoxy-9H-Carbazole in drug substances such as Carvedilol (U.S. Pharmacopoeia (USP), 32NF-27,British pharmacopoeia (BP), 2009, Martindale $35^{\text {th }}$ edition) This 4-Oxiranylmethoxy-9H-Carbazole have been identified as potential genotoxic impurity. LC-MS was found to be more promising and the limit of quantification was $15 \mu \mathrm{g} / \mathrm{gm}$.
\end{abstract}

Keywords: HPLC; LC-MS; Genotoxins; Carvedilol; 4-Oxiranylmethoxy9H-Carbazole

\section{Introduction}

4-Oxiranylmethoxy-9H-Carbazole is generally used as an important intermediate in the preparation of pharmaceutical compounds such as antihipertensives. However, this 4-Oxiranylmethoxy-9H-Carbazole is found to be a genotoxic product. This Genotoxic compounds affects the human genes, and the presence of these genotoxins in the pharmaceutical compounds can be controlled. In current regulatory practice (ICH Guidelines 2002), genotoxic compounds are usually considered to operate by a non-threshold mode of action and, thus any level of exposure carries at least theoretically a risk. This precautions view implies that pharmaceutical measurements should be guided by the so called 'ALARA' principle (As Low As Reasonably Achievable), i.e., where avoidance is not possible, genotoxic impurities must be kept to a low level. However, the draft guidelines from European agency (Guidelines on the limits of Genotoxic impurities CPMP/SWP/5199/02, EMEA/CHMP/QMP/251344/2006, EMEA/CHMP/SWP/431994/2007) and feedback from the US food and drug administration (USFDA) (USFDA, Guidance for Industry 2008) to pharmaceutical industries via drug application has enabled the pharmaceutical industries to establish interim strategies. Generally the daily intake of these genotoxins has been limited to a daily dose of $1.5 \mu \mathrm{g} / \mathrm{day}$. Therefore it is preferable for the potential genotoxins to be controlled during the synthesis; where the levels cannot be controlled and no safety data yet exists it may be preferable for the pharmaceutical company to change the route of synthesis of the drug substances. As 4-Oxiranylmethoxy-9HCarbazole is also a genotoxic compound, the regulatory team may be expected to estimate the levels of 4-Oxiranylmethoxy-9H-Carbazole to be controlled to $15 \mathrm{ppm}$ in the drug substance. It was felt necessary to develop simple, sensitive validated method for 4-Oxiranylmethoxy9H-Carbazole.

\section{Experimental}

\section{Sample, chemicals and reagents}

Carvedilol was synthesized from the CRD research department in APL Research centre, (A Division of Aurobindo Pharma Ltd.) (Bachupally, Quthubullapur, Hyderabad-90, INDIA). Acetonitrile (HPLC grade), Ammonium acetate (BDH grade), High pure water was prepared by using the Milli-Q plus purifier.

\section{Preparation of solution}

Preparation of standard stock solution: Accurately weigh and transfer about $10 \mathrm{mg}$ of 4-Oxiranylmethoxy-9H-Carbazole working

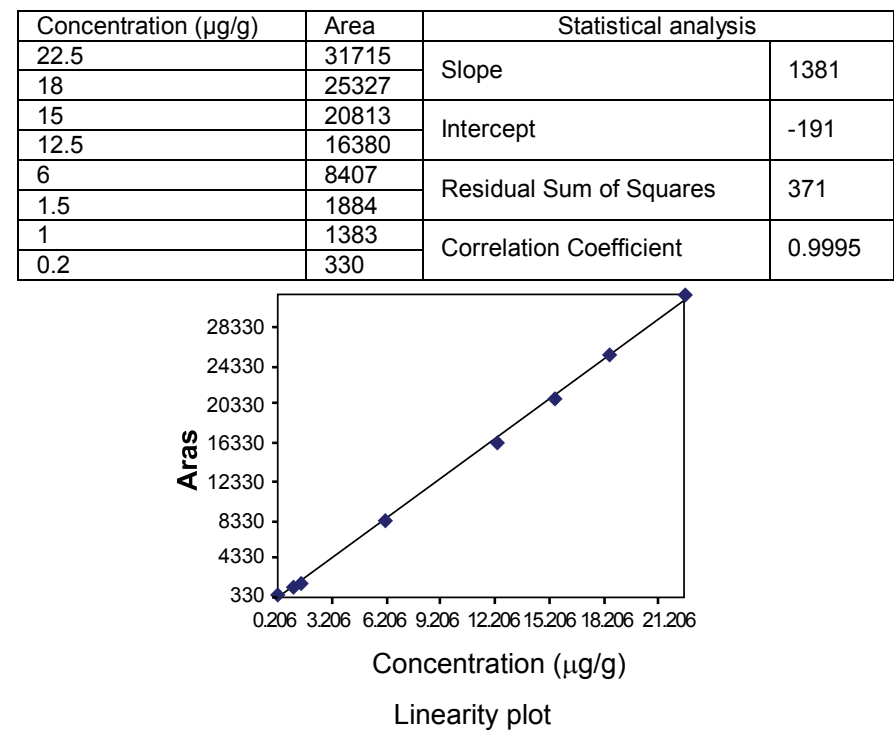

Table 1: Results of linearity study.

standard into a $100 \mathrm{ml}$ volumetric flask $(0.10 \mu \mathrm{g} / \mathrm{ml})$. Dilute $10 \mathrm{ml}$ of this solution to $100 \mathrm{ml}$ with diluents $(0.01 \mu \mathrm{g} / \mathrm{ml})$. Further dilute 10 $\mathrm{ml}$ of this solution to $100 \mathrm{ml}$ with diluents $(0.001 \mu \mathrm{g} / \mathrm{ml})$.

Preparation of standard stock solution: Transfer accurately $7.5 \mathrm{ml}$ of 4-Oxiranylmethoxy-9H-Carbazole Stock solution in $100 \mathrm{ml}$ clean $(15$ $\mu \mathrm{g} / \mathrm{gm}$ with respect to sample concentration $5 \mathrm{mg} / \mathrm{ml}$ ). Spectrogram is shown in the Figure 1.

\section{Instrumentation}

Mass spectrometry: The LC-MS/MS system was used for method

*Corresponding author: M. Srinivasa Rao, APL Research Centre (A Division of Aurobindo Pharma Ltd.), 313, Bachupally, Quthubullapur, Hyderabad 500090, India, Tel: +91 40 23040261; Fax: +91 40 23042932; E-mail: metta_cnu@yahoo.co.in

Received July 02, 2010; Accepted August 23, 2010; Published August 23, 2010

Citation: Srinivasa Rao M, Rao SV, Ray UK, Siva Kumar GS, Sharma HK, et al. (2010) Quantification of 4-Oxiranyl Methoxy-9h-Carbazole a Genotoxic Impurity in Carvedilol Drug Substances by Lc-Ms. J Bioanal Biomed 2: 091-095. doi:10.4172/1948-593X.1000029

Copyright: (c) 2010 Srinivasa Rao M, et al. This is an open-access article distributed under the terms of the Creative Commons Attribution License, which permits unrestricted use, distribution, and reproduction in any medium, provided the original author and source are credited. 
Citation: Srinivasa Rao M, Rao SV, Ray UK, Siva Kumar GS, Sharma HK, et al. (2010) Quantification of 4-Oxiranyl Methoxy-9h-Carbazole a Genotoxic Impurity in Carvedilol Drug Substances by Lc-Ms. J Bioanal Biomed 2: 091-095. doi:10.4172/1948-593X.1000029
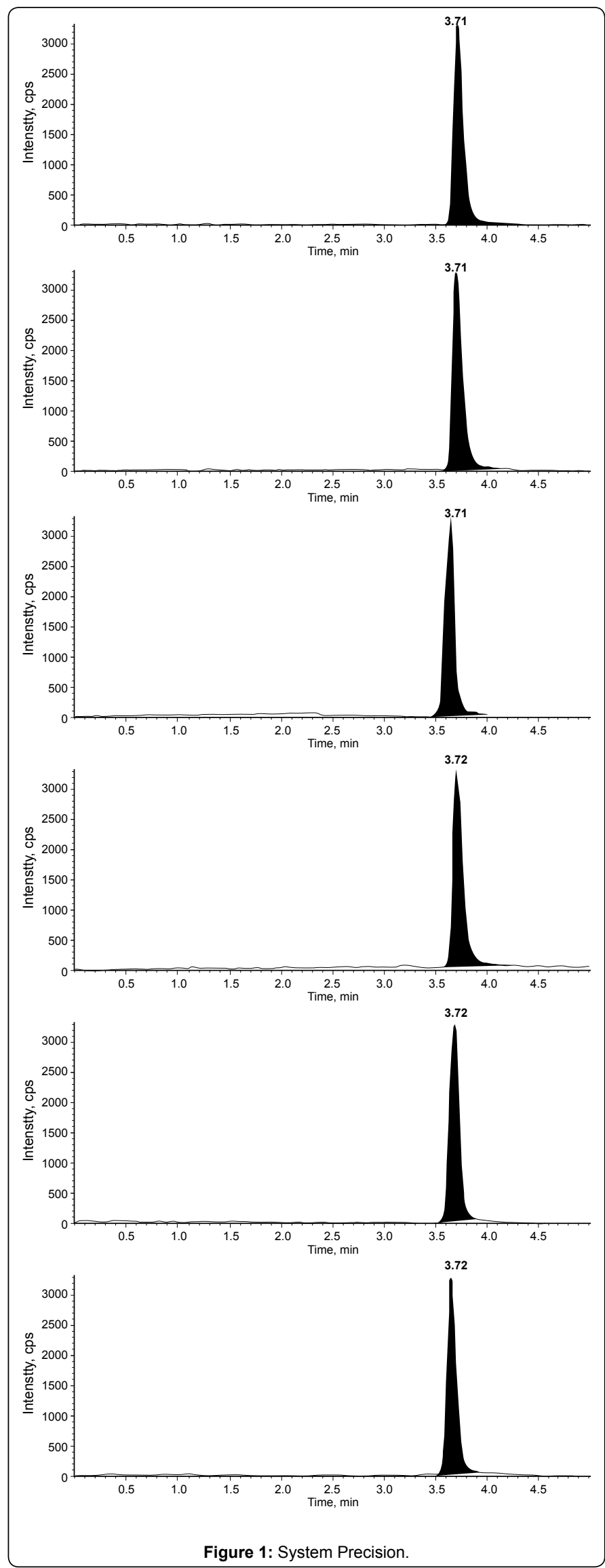

development and validation was done in Applied Biosystems Sciex API 2000 model coupled with Shimadzu HPLC system with mass detector and auto sampler was used in the experiment. Data acquisition and processing were conducted by using the Analyst software.

\section{LC-MS/MS analysis}

LC-MS/MS analysis was carried out using Perkin Elmer triple

\begin{tabular}{|c|c|c|}
\hline \multirow{2}{*}{ Injection ID } & \multicolumn{2}{|c|}{ Area } \\
\cline { 2 - 3 } & LOD & 4-Oxiranylmethoxy-9H-Carbazole \\
\hline 1 & 1148 & LOQ \\
\hline 2 & 988 & 3426 \\
\hline 3 & 1140 & 3693 \\
\hline 4 & 1044 & 3655 \\
\hline 5 & 1115 & 3922 \\
\hline 6 & 1273 & 3833 \\
\hline Mean & 1118 & 4153 \\
\hline SD & 98 & 3780 \\
\hline$\%$ RSD & 8.8 & 249 \\
\hline Conc. $(\mu \mathrm{g} / \mathrm{g})$ & 0.825 & 6.6 \\
\hline
\end{tabular}

Note: SD: Standard deviation, RSD: Relative Standard deviation

Table 2: Results of LOD and LOQ study.

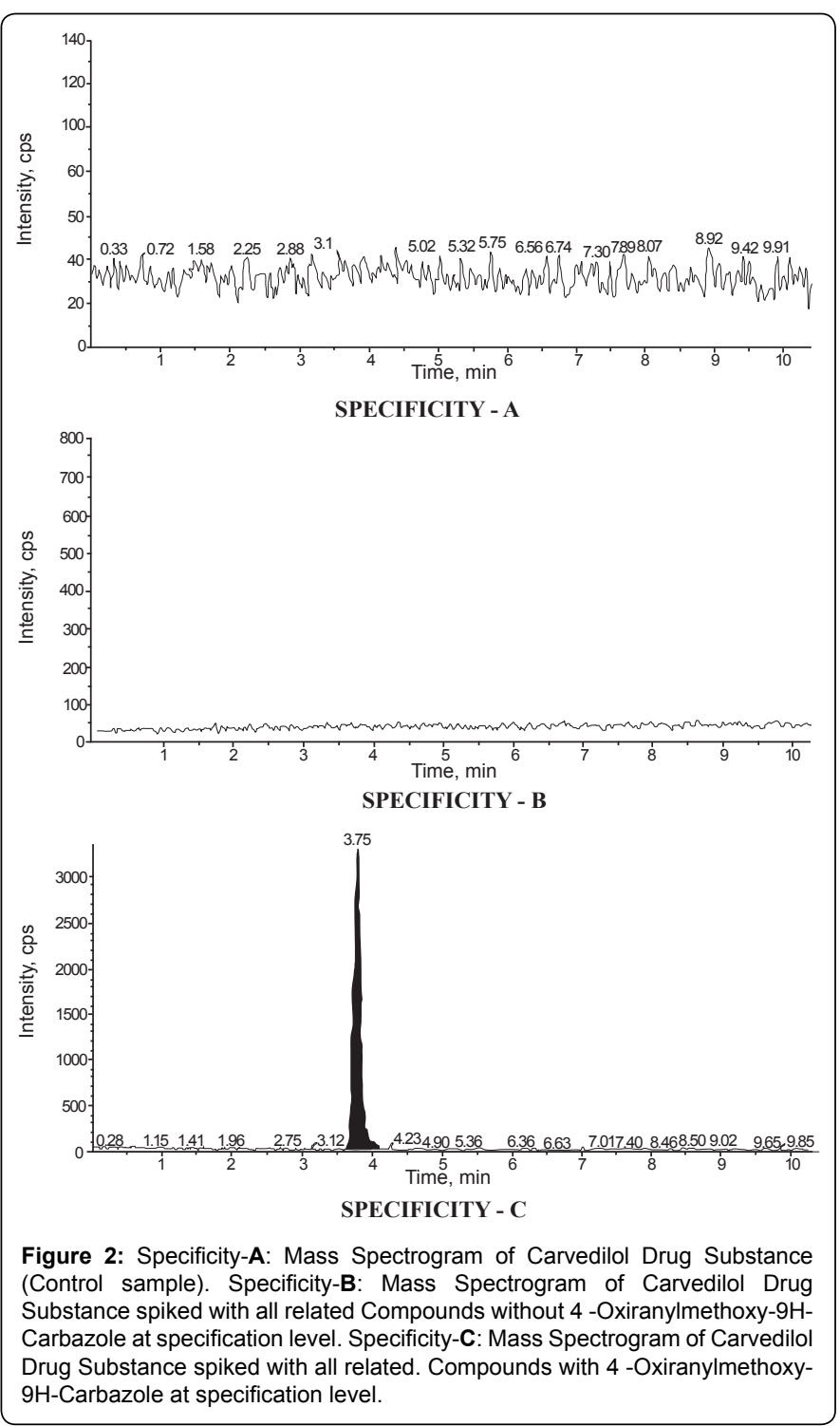


quadrupole mass spectrometer (API 2000, PE SCIEX) coupled with Shimadzu HPLC equipped with SPD 10 A VP UV-VIS detector and LC 10 AT VP pumps. Analyst software was used for data acquisition and data processing. The turbo ion spray voltage was maintained at -4.5 $\mathrm{Kv}$ and temperature was set at $375^{\circ} \mathrm{C}$. The auxiliary gas and sheath gas used was high pure Nitrogen. Zero air was used as Nebulizer gas. The analysis was carried out using YMC PACK C8 250 X $4.6 \mathrm{~mm}$ column with $5 \mu \mathrm{m}$ particle diameter with mobile phase consisting of a mixture of $0.01 \mathrm{M}$ Ammonium acetate $\mathrm{pH}-5$ in water and acetonitrile in the ratio of $15: 85 \mathrm{v} / \mathrm{v}$. The flow rate was $1 \mathrm{ml} / \mathrm{min}$ with flow rate split down to $0.2 \mathrm{ml} / \mathrm{min}$ in to the LC-MS system. The column was monitored at $55^{\circ} \mathrm{C}$.The injection volume was $20 \mu \mathrm{l}$. Electrospray ionization in negative mode was used with a multiple reaction monitoring (MRM) mode was used as MS method for quantification of 4-Oxiranylmethoxy-9H-Carbazole in drug substances. In this method
4-Oxiranylmethoxy-9H-Carbazole is monitored by its molecular ion value of $238.10(\mathrm{M}-\mathrm{H})$ and its daughter ion 181.0 with focusing potential-270, declustering potential -25, entrance potential -10, and the curtain gas flow 25 (psi) respectively.

\section{Results and Discussion}

The main target of LC-MS/MS method was to quantification of 4-Oxiranylmethoxy-9H-Carbazole impurity in the Carvedilol active ingredient. During the method development we used different reversed phase stationary and mobile phase was used and finally chromatographic separation was achieved on a YMC PACK C8 $250 * 4.6,5 \mathrm{mic}$ column (YMC) in isocratic mode using with $0.01 \mathrm{M}$ Ammonium acetate $\mathrm{pH}-5$ in water and Acetonitrile in the ratio of $15: 85 \mathrm{v} / \mathrm{v}$. The flow rate was $1.0 \mathrm{ml} / \mathrm{min}$ split down to $0.2 \mathrm{ml} / \mathrm{min}$ in to LC-MS system.
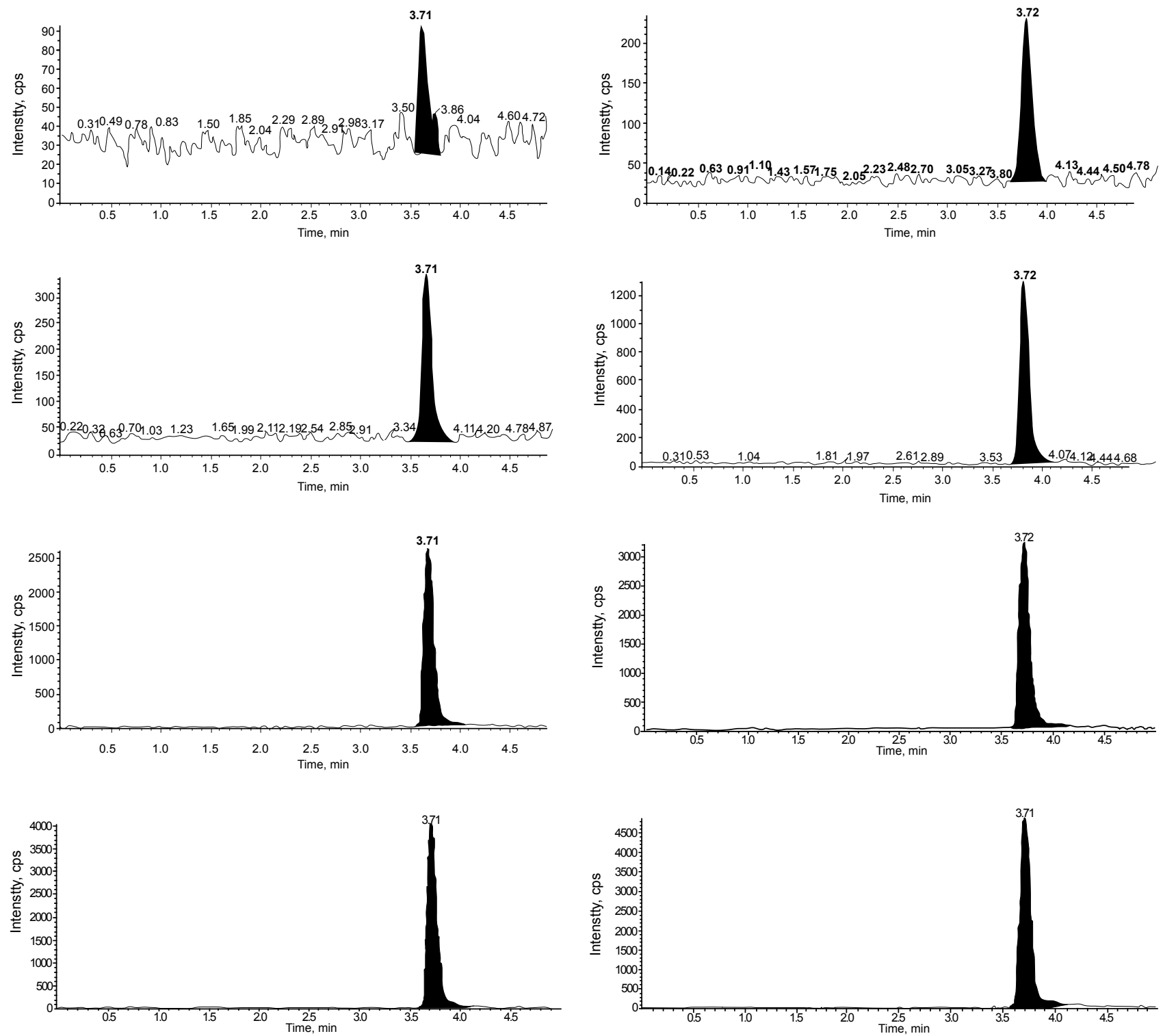

Figure 3: Linearity mass spectrogram of 4 -Oxiranylmethoxy-9H-Carbazole. 


\begin{tabular}{|c|c|c|c|c|c|c|c|}
\hline \multirow{2}{*}{\multicolumn{2}{|c|}{$\begin{array}{c}\text { Sample ID } \\
\text { LOQ Level } \\
\text { Sample } 1\end{array}$}} & \multirow{2}{*}{\multicolumn{2}{|c|}{$\begin{array}{c}\begin{array}{c}\text { Amount } \\
\text { added } \\
(\mu \mathrm{g} / \mathrm{g})\end{array} \\
2.679\end{array}$}} & \multirow{2}{*}{$\begin{array}{c}\begin{array}{c}\text { Amount } \\
\text { found } \\
(\mu \mathrm{g} / \mathrm{g})\end{array} \\
2.7600\end{array}$} & \multirow{2}{*}{$\begin{array}{c}\begin{array}{c}\% \\
\text { Recovery }\end{array} \\
103.0\end{array}$} & \multicolumn{2}{|c|}{ Statistical Analysis } \\
\hline & & & & & & Mean & 96.1 \\
\hline \multicolumn{2}{|c|}{$\begin{array}{l}\text { LOQ Level } \\
\text { Sample } 2\end{array}$} & \multicolumn{2}{|c|}{2.681} & 2.4240 & 90.4 & SD & 6.39 \\
\hline \multicolumn{2}{|c|}{$\begin{array}{l}\text { LOQ Level } \\
\text { Sample } 3\end{array}$} & \multicolumn{2}{|c|}{2.680} & 2.5410 & 94.8 & $\%$ RSD & 6.6 \\
\hline \multicolumn{2}{|c|}{$\begin{array}{c}100 \% \text { Level } \\
\text { Sample } 1\end{array}$} & \multicolumn{2}{|c|}{15.445} & 15.5480 & 100.7 & Mean & 97.7 \\
\hline \multicolumn{2}{|c|}{$\begin{array}{c}100 \% \text { Level } \\
\text { Sample } 2\end{array}$} & \multicolumn{2}{|c|}{15.491} & 14.2500 & 92.0 & SD & 4.91 \\
\hline \multicolumn{2}{|c|}{$\begin{array}{c}\text { 100\% Level } \\
\text { Sample } 3\end{array}$} & \multicolumn{2}{|c|}{15.454} & 15.5000 & 100.3 & $\%$ RSD & 5.0 \\
\hline \multicolumn{2}{|c|}{$\begin{array}{c}\text { 150\% Level } \\
\text { Sample } 1\end{array}$} & \multicolumn{2}{|c|}{23.181} & 24.4420 & 105.4 & Mean & 101.5 \\
\hline \multicolumn{2}{|c|}{$\begin{array}{l}150 \% \text { Level } \\
\text { Sample } 2\end{array}$} & \multicolumn{2}{|c|}{23.204} & 22.5190 & 97.0 & SD & 4.24 \\
\hline \multicolumn{2}{|c|}{$\begin{array}{c}150 \% \text { Level } \\
\text { Sample } 3\end{array}$} & \multicolumn{2}{|c|}{23.195} & 23.6960 & 102.2 & $\%$ RSD & 4.2 \\
\hline \multicolumn{8}{|c|}{ Overall Statistical Analysis } \\
\hline Mean & 98.4 & SD & 5.16 & $\%$ RSD & 5.2 & $\begin{array}{c}95 \% \\
\text { Confidence } \\
\text { Interval }\end{array}$ & $\stackrel{ \pm}{ \pm}$ \\
\hline
\end{tabular}

Note: SD: Standard deviation, RSD: Relative Standard deviation

Table 3: Results of recovery study.

\section{Validation of the method for 4-oxiranylmethoxy-9H-carbazole in carvedilol}

Specificity of 4-Oxiranylmethoxy-9H-Carbazole: Solutions are prepared using Carvedilol drug substance (Control Sample), Spiked with all the related substances in Carvedilol drug substance except 4-Oxiranylmethoxy-9H-Carbazole (Specificity-A) and Spiked with all the related substances including 4-Oxiranylmethoxy-9H-Carbazole in Carvedilol at specification level and subjected for LC-MS/MS study for the evaluation of specificity. The sample spiked with all other impurities without 4-Oxiranyl methoxy-9H-Carbazole at specification level, do not show any relevant response in spectrogram. The sample spiked with all other impurities along with 4-Oxiranylmethoxy$9 \mathrm{H}-$ Carbazole (Specificity-B) at specification level shows response equivalent to standard in spectrogram at retention time of 4-Oxiranylmethoxy-9H-Carbazole ( $\mathrm{m} / \mathrm{z}-238.10 \mathrm{M}-\mathrm{H}$ and 181.0$)$ hence the method is specific and selective. Spectrogram is shown in the Figure 2.

Linearity of 4-Oxiranylmethoxy-9H-Carbazole: By selecting ion monitoring, the linearity of 4-Oxiranylmethoxy-9H-Carbazole was satisfactorily done a series of solutions were prepared using 4-Oxiranylmethoxy-9H-Carbazole at concentration levels from around detection level to $150 \%$ and the concentration levels are $22.5(\mu \mathrm{g} / \mathrm{g})$, $18(\mu \mathrm{g} / \mathrm{g}), 15(\mu \mathrm{g} / \mathrm{g}), 12.5(\mu \mathrm{g} / \mathrm{g}), 6(\mu \mathrm{g} / \mathrm{g}), 1.5(\mu \mathrm{g} / \mathrm{g}), 1(\mu \mathrm{g} / \mathrm{g})$ and 0.2 $(\mu \mathrm{g} / \mathrm{g})$ respectively. The peak area versus concentration data was done by linearity plot slop, intercept, and residual sum of squares analysis. The calibration curve was given based on response over the concentration range for 4-Oxiranylmethoxy-9H-Carbazole. The correlation coefficients for 4-Oxiranylmethoxy-9H-Carbazole were 0.999. Linearity of the 4-Oxiranylmethoxy-9H-Carbazole spectrogram was shown in the Figure 3 and the results are tabulated in Table 1.

Limit of detection (LOD) and Limit of Quantification (LOQ) for 4-Oxiranylmethoxy-9H-Carbazole: The LOD and LOQ values of 4-Oxiranylmethoxy-9H-Carbazole were predicted from the linearity data. Each predicted concentration was verified for precision by preparing the solutions at about predicted concentration and injecting each solution six times for LC-MS/MS study and the predicted concentration for LOQ was $2.68(\mu \mathrm{g} / \mathrm{g})$ and LOD was $0.825(\mu \mathrm{g} / \mathrm{g})$. The
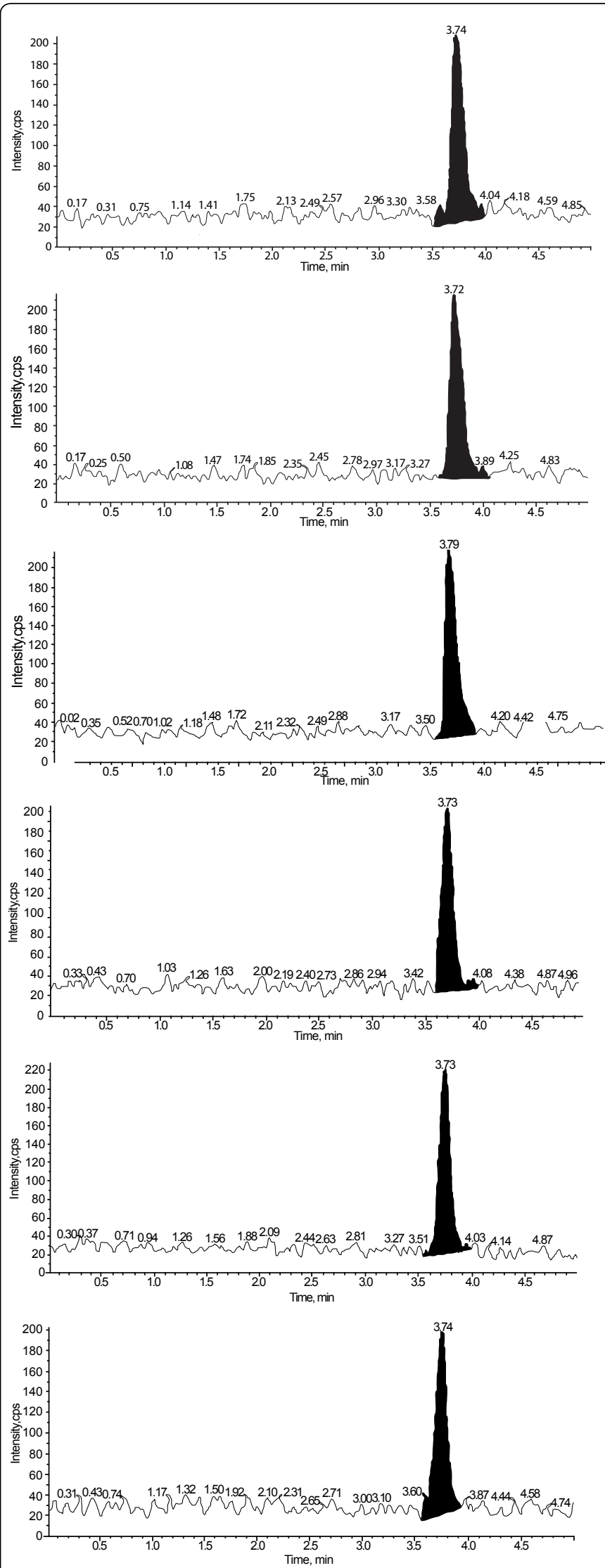

Figure 4: LOD precision mass spectrogram of 4 -Oxiranylmethoxy-9HCarbazole. 
spectrograms are shown in Figure 4 and Figure 5 (Figure 5 is included in supplementry data). Further the results are tabulated in Table 2.

Recovery of 4-oxiranylmethoxy-9H-carbazole from the API: The accuracy of the method was evaluated in sample solutions were prepared in triplicate by spiking 4-Oxiranylmethoxy-9H-Carbazole at LOQ level to $150 \%$ with Carvedilol drug substance and injected each solution in to LCMS as per methodology. The percentage of recovery was calculated. A satisfactory value of 4-Oxiranylmethoxy$9 \mathrm{H}$-Carbazole $(96.10 \%, 97.70 \%$ and $101.5 \%)$ was found. At such low levels these recoveries and \% RSD were satisfactory. Accuracy at LOQ to $150 \%$ level spectrogram is shown in Figure 6 and Figure 7 (Figure 6 and Figure 7 is included in supplementry data), further the results are tabulated in Table 3.

\section{Conclusion}

LC-MS/MS method has been suitable for quantification of 4-Oxiranylmethoxy-9H-Carbazole for highly sensitive method of analysis with limit of detection $0.825 \mathrm{ppm}$. The methodology has one of the restrictions of 4-Oxiranylmethoxy-9H-Carbazole in Carvedilol sample.

\section{Acknowledgement}

The authors gratefully acknowledge the management of Aurobindo Pharma Limited, in general and APL Research Centre in particular for allowing us to carry out the present work. The authors are also thankful to the colleagues of Analytical research department and Chemical research department.

\section{References}

1. British pharmacopoeia (BP), pg374 2009.

2. EMEA Q\&A EMEA/CHMP/SWP/43994/2007.

3. Guidelines on the limits of Genotoxic impurities EMEA-CIIMP/ QMP/251344/2006, 28 June, 2006.

4. International conference on Harmonization (ICH) Guidelines, Q3A(R): Impurities in new drug substance February 2003.

5. Martindale 35th edition pg1114.

6. The European medicines agency (EMEA), committee for medical products for Human use (CHMP), Guidelines on the limits of Genotoxic impurities CPMP/ SWP/5199/02.

7. U.S. Pharmacopoeia. (USP32 NF-27) (2007) 4036.

8. US FDA, Guidence for industry: genotoxic and carcinogenic impurities in drug substances and products: recommended approaches (draft), December 2008. 